\title{
TEMA 16-2014: Síndrome de Obstrucción Intestinal
}
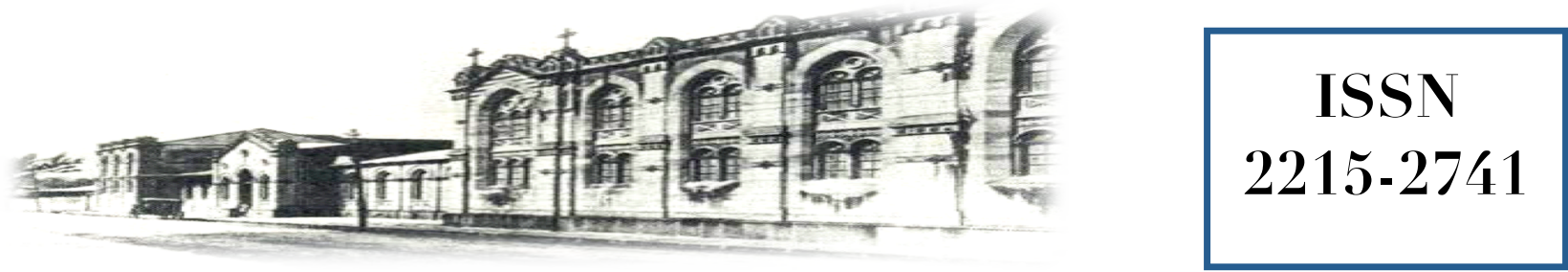

Hospital San quan de Dias, San José. Costa Rica. Fundado en 1845

$\begin{array}{ll}\text { Recibido: } & 18 / 03 / 2014 \\ \text { Aceptado: } & 24 / 04 / 2014\end{array}$

Ronny Granados Quesada ${ }^{1}$ Julia Vargas Carranza ${ }^{2}$

\footnotetext{
${ }^{1}$ Médico General Servicio Cirugía Ambulatoria. Hospital San Juan de Dios. Universidad de Ciencias Médicas. Correo electrónico: ronnygq10@hotmail.com

${ }^{2}$ Médica Especialista en Cirugía General. Jefe Servicio Cirugía 1 y Cirugía Ambulatoria. Hospital San Juan de Dios. Profesora de la Cátedra de Cirugía UCR. Departamento Clínico HSJD
}

\section{RESUMEN}

La obstrucción intestinal es un conjunto de signos y síntomas que se pueden producir por diversas patologías luminales (bezoares, litos), extraluminales (adherencias) o intramurales (enfermedad de Crohn) del tracto gastrointestinal, peritoneales y sistémicas, que dan como problema principal la imposibilidad de canalizar gases y evacuar el contenido intestinal. Ocupa un $20 \%$ de las admisiones quirúrgicas agudas y es una de las causas más frecuentes de intervención quirúrgica.

\section{PALABRAS CLAVE}

Obstrucción intestinal. Síndrome. Patologías.

\begin{abstract}
The intestinal obstruction syndrome is present when there exists an interference with the normal transit of intestinal contents. Such obstruction can result from extraluminal (adhesions), intraluminal (bezoars, gallstones) or intramural (Crohn's disease) processes. The main complaint is the difficulty in passing flatus and stools. This syndrome produces $20 \%$ of all the acute surgical admissions and is one of the most important etiologies for surgical intervention.
\end{abstract}

\section{KEY WORDS}

Intestinal obstruction. Syndrome. Pathology. 


\section{INTRODUCCIÓN}

La obstrucción intestinal es la interrupción del tránsito intestinal en sentido buco-caudal, que puede ser secundaria a un bloqueo de la luz intestinal (obstrucción mecánica) o bien a la ausencia de motilidad intestinal (íleo paralítico). Aunque esta última es la entidad más común, por lo general cede por sí mismo y no requiere intervención quirúrgica. Por su parte, la obstrucción mecánica puede obedecer a factores intrínsecos o extrínsecos y a menudo precisa intervención definitiva en un periodo relativamente breve, para determinar su causa y minimizar la morbilidad y mortalidad subsecuentes.

La obstrucción intestinal puede presentarse en cualquier etapa de la vida; la causa varía de acuerdo con el grupo de edad. Sin embargo, el padecimiento es más frecuente en la cuarta y quinta décadas de la vida, si bien en los últimos 65 años la causa más frecuente de obstrucción ha cambiado. El $80 \%$ de las obstrucciones intestinales se presenta en el intestino delgado y el resto en el colon ${ }^{(1)}$.

\section{DISCUSIÓN}

\section{Historia}

La oclusión intestinal es conocida desde los tiempos de Hipócrates; él fue precisamente quien utilizó la palabra "íleo" ("yo retuerzo" en griego). En 1884 Sir Frederick Treves obtuvo el primer lugar del premio jacksoniano, otorgado por el Council of the Royal College of Surgenos of England, por su ensayo sobre la obstrucción intestinal; en este trabajo Treves definió la enfermedad de la siguiente manera:

"Bajo el título de obstrucción intestinal se incluyen diversos procesos que, aunque de carácter distinto, poseen la capacidad común de obstruir el paso de materia a lo largo del intestino".

Este estudio reflejaba la experiencia del London Hospital y dentro de sus conclusiones aconsejaba la intervención quirúrgica temprana para resolver la anomalía.

En 1885 Thomas Bryant estableció las diferencias entre las oclusiones simples y las estranguladas. Schwartz, en 1911, estudió distintas imágenes radiológicas de obstrucción intestinal. También en ese mismo año Murphy y Vincent aclararon la naturaleza de la estrangulación y la función fundamental de la obstrucción venosa $^{(1)}$.

\section{Definiciones}

Obstrucción simple: aquella en la que no existe compromiso vascular.

Ileo: es una entidad que denota la falla del pasaje hacia adelante del contenido intestinal, debido a una falla funcional, por ejemplo en el íleo adinámico que se produce cuando hay alteración en la concentración de electrolitos séricos, como en el caso de la hipocalemia. Generalmente no es doloroso.

Obstrucción mecánica: es un bloqueo intraluminal.

Obstrucción en asa cerrada: en un intestino que se obstruye en la porción proximal y distal, como en la torsión de un vólvulos de intestino grueso o una incarceración herniaria, como en las hernias internas.

Estrangulación: se habla de una obstrucción luminal pero con compromiso del riego sanguíneo y compromiso en la viabilidad tisular.

Obstrucción alta: es aquella que se produce por encima del ligamento de Treitz, por ejemplo en la hipertrofia congénita del píloro y baja es la que rebasa este límite en forma distal, por ejemplo en el íleo biliar.

Obstrucción aguda o crónica: en referencia con el tiempo que tiene el proceso cerrando parcial y gradualmente la luz intestinal, hasta su totalidad o cuando sucede un mecanismo de válvula o de torsión o acodamiento y distorsión como por ejemplo en las adherencias ${ }^{(2)}$.

\section{Etiología}

\section{Obstrucción de intestino delgado}

Las principales causas de obstrucción de esta parte del intestino se engloban en las causas generales de la obstrucción, ya que al ser la parte más larga de las vísceras huecas, se encuentra 
más expuesto a sufrir alguna patología que lo obstruya.

1. Adherencias. Es la causa más frecuente de obstrucción, en más del $90 \%$ de los casos en pacientes con historia previa de cirugía intraabdominal generalmente complicada como en la úlcera péptica perforada y peritonitis generalizada secundaria. Las adherencias se producen por una reacción exagerada del organismo por limitar y reparar así como para evitar mayor daño, pueden ser laxas que se despegan fácilmente o fibrosas en relación con una reacción inflamatoria local más intensa, como en una apendicitis perforada con peritonitis localizada.

2. Hernias. La segunda causa más frecuente de obstrucción en general y la primera en pacientes que no han sido intervenidos quirúrgicamente. Las hernias se clasifican en internas (como la obturatriz y la que se da a través de un defecto del mesenterio que no se suturó durante una resección intestinal posterior a la anastomosis) y la externa como, cualquier hernia de la pared abdominal, tales como la inguinal o la femoral. Las hay congénitas como la hernia de Bodeleck del diafragma o adquiridas como las hernias postincisionales luego de cierres defectuosos de la pared abdominal.

\section{Otras causas de obstrucción:}

\section{Extrínsecas}

1. Carcinomatosis o tumor adherido que no sea de origen intestinal.

2. Absceso intraabdominal.

3. Hematoma.

4. Malrotación con bandas de Ladd o vólvulos del intestino medio.

5. Páncreas anular.

6. Endometriosis.

7. Síndrome de la arteria mesentérica superior con compresión de la tercera porción del duodeno en pacientes muy adelgazados.

\section{Intrínsecas}

1. Tumores neoplásicos del intestino delgado

2. Lesiones congénitas

- Atresia de intestino delgado, estenosis o membranas.

- Duplicación del intestino delgado o quistes mesentéricos.
- Divertículo de Meckel u otros remanentes del conducto onfalomesentérico.

3. Lesiones inflamatorias

- Enteritis regional y enfermedad de Crohn.

- Enteritis pos radiación y estenosis.

- Obstrucción intestinal intraluminal.

- Ileo meconial.

- Ileo biliar.

- Intususcepción.

- Cuerpos extraños.

4. Otras condiciones que semejan una obstrucción de intestino delgado:

- Obstrucción colónica derecha.

- Íleo adinámico.

- Insuficiencia vascular:

- Embolismo mesentérico.

- Isquemia mesentérica secundaria a hipoperfusión.

- Trombosis mesentérica.

5. Enfermedad de Hirschsprung

\section{Obstrucción de intestino grueso}

\section{Extrínsecas}

1. Adherencias.

2. Hernias.

3. Vólvulos principalmente de sigmoides en un $80 \%$ y del ciego en un $20 \%$.

4. Endometriosis.

\section{Intrínsecas}

1. Carcinoma de colon en un $60 \%$ de los casos.

2. Lesiones congénitas como el ano imperforado.

3. Lesiones inflamatorias.

- Colitis ulcerativa.

- Diverticulitis.

- Enteritis postradiación.

4. Obstrucción intraluminal

- Íleo meconial.

- Intususcepción.

- Impactación fecal, cuerpos extraños.

5. Otras condiciones que pueden semejar obstrucción de intestino grueso

- Íleo adinámico.

- Enfermedad de Hirschsprung.

- Colitis focal isquémica.

Debido a la importancia que tiene en la práctica clínica y a los múltiples factores que intervienen en su presentación y complicaciones, se presenta 
con más detalle los aspectos referentes al Íleo Adinámico, cuyo diagnóstico temprano y tratamiento es clave en el manejo de los pacientes que lo $\operatorname{presentan}^{(3)}$.

\section{Íleo}

\section{Adinámico}

1. Metabólico:

- Hipocalemia.

- Hipomagnesemia.

- Hiponatremia.

- Cetoacidosis.

- Uremia.

- Porfiria.

- Intoxicación por metales pesados.

2. Respuesta a proceso inflamatorio local en la cavidad peritoneal.

3. Peritonitis difusa.

4. Procesos retroperitoneales.

- Hematoma retroperitoneal.

- Pancreatitis.

5. Drogas

- Fractura espinal o pélvica.

- Narcóticos.

- Antipsicóticos.

- Anticolinérgicos.

- Bloqueadores ganglionares.

- Antiparkinsonianos.

6. Desórdenes neuropáticos.

- Diabetes mellitus.

- Esclerosis múltiple.

- Escleroderma.

- Lupus eritematoso sistémico.

- Enfermedad de Hirschsprung.

7. Íleo posoperatorio: seguido de cirugía intraperitoneal. La motilidad de intestino delgado regresa a partir de 24 a 48 h; la motilidad gástrica regresa a las 48 h y la motilidad colónica regresa a partir de las $72 \mathrm{~h}$.

8. Síndrome de Ogilvie: Pseudoobstrucción colónica de etiología incierta. Se describe como un proceso retroperitoneal, que se asocia a debilitamiento, enfermedad crónica, inmovilidad, decúbito prolongado y polifarmacia. Se manifiesta usualmente por dilatación moderada del ciego y una dilatación del ciego mayor o igual a $12 \mathrm{~cm}$ incrementa la posibilidad de perforación.

9. Trauma abdominal con hematoma de la pared intestinal.

\section{Fisiopatología}

La obstrucción intestinal produce cambios importantes en la absorción y secreción de líquidos intestinales. En condiciones normales el intestino posee una gran capacidad de absorción y pasan a él entre 8 y 12 litros de secreciones (biliares, pancreáticas, gástricas e intestinales) que se resorben en su mayoría; 400 a $500 \mathrm{ml}$ llegan a la válvula ileocecal y sólo entre 150 y $200 \mathrm{ml}$ de agua se excretan por las heces. En las fases iniciales de la obstrucción $(<12$ h) se acumulan líquidos $\mathrm{y}$ electrolitos a nivel intraluminal debido a las alteraciones de la absorción intestinal.

Después de 24 horas se acumulan no sólo agua y electrolitos sino también, en forma evidente, una secreción intestinal que es producida por gradientes osmóticos y por presión hidrostática. La ingestión de líquidos y aire deglutido provoca la distensión intestinal inicial. Gran parte del gas que participa en la obstrucción proviene del aire deglutido (el aire que producen las bacterias contribuye en realidad en forma mínima).

En los estudios se ha apreciado en forma clínica que al principio aumenta la frecuencia e intensidad de las contracciones, lo cual genera cólicos. Posteriormente ocurre distensión del asa intestinal y la motilidad disminuye, tal vez como consecuencia de la hipoxia secundaria a la absorción de nitrógeno en la luz intestinal. La distensión induce el reflejo del vómito, que incrementa la pérdida de líquidos.

La irrigación arterial del intestino es inversamente proporcional a la presión intraluminal. En forma experimental se sabe que presiones de $30 \mathrm{mmHg}$ interrumpen el flujo capilar intestinal y que las presiones mayores de $60 \mathrm{mmHg}$ detienen el flujo de algunos vasos. Esto puede ocasionar hipoxia en la mucosa, después en la pared y al final en la serosa (con perforación).

En casos de obstrucción la microflora cambia de modo radical cualitativa y cuantitativamente y los gérmenes aislados pueden llegar inclusive hasta $10^{9}$ por $\mathrm{ml}$ (E. coli, S. faecalis, Klebsiella, Proteus, Clostridium y bacteroides). La flora prolifera en relación directa con el tiempo y la longitud de la obstrucción. 
Los efectos sistémicos de la oclusión intestinal se deben sobre todo a la pérdida de agua y electrolitos, la hipocalemia, la acidosis metabólica y la hipocloremia ${ }^{(4)}$.

\section{Oclusión intestinal según la edad}

Neonatos: se debe considerar la etiología congénita como el íleo meconial o la enfermedad de Hirschsprung así como ano imperforado.

Niños: se debe buscar hernia inguinal estrangulada e intususcepción, entre otras.

Adultos jóvenes: herniaciones y enfermedad inflamatoria del intestino.

Adultos: secundaria a adherencias, hernia o cáncer.

Ancianos: mismas etiologías más enfermedad diverticular e impactacion fecal.

Tabla 1. Causas más frecuentes de obstrucción intestinal según grupo etáreo.

\begin{tabular}{|c|c|}
\hline Grupo & Causas \\
\hline Neonatos & $\begin{array}{l}\text { Atresia congénita } \\
\text { Vólvulo Neonatal } \\
\text { Íleo Meconial } \\
\text { Enfermedad de Hirschprung } \\
\text { Ano imperforado }\end{array}$ \\
\hline Niños & $\begin{array}{l}\text { Hernia inguinal estrangulada } \\
\text { Intusucepción Intestinal } \\
\text { Complicaciones por Divertículo de } \\
\text { Meckel } \\
\text { Enfermedad de Hirschprung }\end{array}$ \\
\hline Adultos & $\begin{array}{l}\text { Adherencias } \\
\text { Hernias } \\
\text { Carcinoma de Colon }\end{array}$ \\
\hline Ancianos & $\begin{array}{l}\text { Adherencias } \\
\text { Hernias } \\
\text { Divertículos } \\
\text { Carcinoma de Colon } \\
\text { Impactación Fecal }\end{array}$ \\
\hline
\end{tabular}

\section{Sintomatología}

Náusea, vómito, obstipación: de acuerdo al nivel de la obstrucción se dan las características del vómito. En la obstrucción a nivel ileal, el tipo de vómito será fecaloide y en la obstrucción pilórica, será de tipo gástrico y con o sin contenido alimentario.
Se puede encontrar pasaje de flatos y excremento distal a la obstrucción, sin que esto indique necesariamente la liberación de la obstrucción. Toda esta sintomatología se inicia una vez que hay un llenado de la porción obstruida con líquido, aire y gas que una vez saturada la máxima capacidad de las asas intestinales, responderán con ondas antiperistálticas para defender la integridad del órgano dando lugar a la náusea y al vómito.

Dolor: el dolor que se presenta es generalmente de tipo cólico, que se localiza en un principio en el centro del abdomen y en el área del órgano afectado y posteriormente se hace generalizado por la inflamación del peritoneo visceral y parietal. Si existe dolor intenso y continuo puede indicar un proceso patológico severo, como en el caso de isquemia, necrosis o perforación por torsión o estrangulamiento de una asa, lo que se manifiesta más gravemente por afectación de una asa de intestino grueso con sepsis temprana y más agresivo, resultando en una tasa de mortalidad más elevada.

Distensión abdominal: es un dato característico de la obstrucción que se produce gradual y progresivamente, hasta que se autolibera por medio del vómito o mediante la aplicación de sonda nasogástrica. Implica la acumulación de jugos digestivos, así como líquido de tercer espacio que se produce por alteraciones en el movimiento de agua y electrolitos a través de la membrana celular, gas y aire deglutido, que lleva al compromiso vascular venoso y posteriormente arterial.

Historia quirúrgica: los procedimientos en la cavidad peritoneal o de la pelvis, pueden inducir a la formación de adherencias o hernias internas, aun en presencia de estomas, la pérdida súbita del gasto a través de éstas indica seguramente la torsión o necrosis del estoma.

Historia médica: en casos de arteriosclerosis, arritmias cardiacas, infarto del miocardio, insuficiencia cardiaca congestiva, así como con el uso de digitálicos, se puede presentar isquemia intestinal. También debe interrogarse por la presencia de enfermedad, inflamatoria del intestino o diverticulitis así como colecistitis crónica litiásica con íleo biliar secundario.

Uso de medicamentos: digitálicos por isquemia, narcóticos y anticolinérgicos por íleo adinámico, 
diuréticos por hipocalemia, polifarmacia en el síndrome de Ogilvie ${ }^{(5)}$.

\section{Exploración \\ Abdominal}

El sonido intestinal es en un principio de tipo borborigmo, seguido de un sonido de lucha, intenso y muy audible, que posteriormente es seguido de abatimiento en la intensidad de los ruidos por fatiga del músculo liso, hasta el silencio abdominal, que habla de un cuadro grave. En el íleo adinámico los sonidos pueden estar ausentes.

En caso de una obstrucción distal de intestino delgado, las oleadas de movimientos peristálticos de lucha se presentan cada 6 o 7 minutos, mientras que en las obstrucciones colónicas las ondas de movimiento serán cada 30 o 40 minutos. El dolor que se encuentra en la exploración física determina, de acuerdo a su intensidad, la urgencia de una intervención, cuando hay datos de irritación peritoneal, que es simplemente el dolor que es buscado con ciertas maniobras sobre el abdomen y que indican la gravedad de la enfermedad.

La distensión del abdomen es otro signo fundamental, cuyo hallazgo puede ser difícil si el paciente ya ha sido manejado con sonda nasogátrica.

Debe buscarse la presencia de masas en la cavidad, como un tumor sólido del retroperitoneo o secundarias a órganos, por ejemplo esplenomegalia, afectados de manera primaria por patología hematológica o parasitaria como en la malaria crónica, o procesos sépticos del tracto digestivo como por ejemplo en un piocolecisto, o por cáncer o tumores quísticos que producen debido a su gran tamaño obstrucción extrínseca, por ejemplo en el quiste mesentérico gigante.

Es muy importante la búsqueda intencionada de defectos herniarios en la pared abdominal. Observar si hay cicatrices quirúrgicas o traumáticas, laceraciones de la pared $o$ hematomas, que podrían hablar de trauma contuso abdominal con lesión secundaria de vísceras sólidas, por ejemplo laceraciones hepáticas o de víscera hueca como los hematomas de la pared intestinal.
También se debe valorar los antecedentes de estudios endoscópicos por la posibilidad de perforaciones. Mucho cuidado se recomienda en los pacientes ancianos por cuadros abigarrados de abdomen agudo e íleo secundario, como en el caso de úlceras pépticas perforadas.

\section{Exploración Rectal y Vaginal}

El ámpula rectal generalmente se encontrará vacía, se deberá descartar impactación fecal o la presencia de tumores rectales, así mismo la presencia de hemorragia que hable de neoplasia de intestino bajo. Se puede palpar bimanualmente en el tacto rectal, por la presencia de tumores sólidos o quísticos de los ovarios que den lugar a patología aguda o crónica y como manifestación la obstrucción intestinal. Tambén es posible descartar la presencia de embarazos ectópicos no rotos, que produzcan un íleo reflejo o masas rectales que se pueden verificar mediante esta exploración ${ }^{(6)}$.

\section{Estudios de}

Laboratorio

Leucocitos: puede haber una cuenta normal si no hay complicaciones. Ésta se eleva marcadamente en las complicaciones. Si hay un proceso infeccioso se encontrará elevada desde el inicio, las formas jóvenes como las bandas se encontrarán en procesos sépticos severos. Usualmente el nivel es menor de $12.000 / \mathrm{mm}^{3}$ en una obstrucción simple; mayores de $20.000 / \mathrm{mm}^{3}$ sugieren una enfermedad vascular mesentérica aguda.

Hematocrito: elevado en los estados como deshidratación, pero disminuidos en hemorragias subclínicas, como en el adenocarcinoma de colon izquierdo.

Alteraciones en los electrolitos: particularmente en la hipocalemia.

Alcalosis: en la obstrucción pilórica secundaria a vómitos de contenido ácido.

Acidosis: secundaria a sepsis como en el caso de un estrangulamiento de asa con infarto intestinal. 


\section{Estudios de \\ Gabinete}

Rx de tórax: se deberá de tomar de pie para detectar aire libre subdiafragmático que hable de perforación de víscera hueca o de una hernia diafragmática.

$\boldsymbol{R} \boldsymbol{x}$ de abdomen: para observar las características clásicas de la obstrucción intestinal con niveles hidroaéreos, borramiento de estructuras o líquido libre en cavidad e imágenes densas como litos, así como ausencia de aire en el ámpula rectal. Se pueden practicar estudios simples o contrastados simples o con doble contraste. Éstos últimos están contraindicados en sospecha de perforación gástrica o intestinal.

Sin embargo el uso de medio de contraste en un tránsito intestinal, apoya para el diagnóstico diferencial de íleo adinámico y obstrucción mecánica en el $80 \%$ de los casos de diagnóstico dudoso. En el íleo adinámico el bario toma 4 a 6 horas en llegar al colon, en la obstrucción total toma una hora o menos para llegar al sitio de la obstrucción $^{(7)}$.

\section{Tratamiento Médico}

Rehidratación: Se debe restituir el volumen con solución salina $0.9 \%$ hasta que haya una adecuada diuresis, al menos de $0.5 \mathrm{ml}$ por $\mathrm{kg}$ de peso por hora.

Corrección del desequilibrio hidroelectrolítico: con soluciones complementadas con $\mathrm{KCl}$.

Sonda de Foley: para monitorizar la diuresis

Sonda nasogástrica: con la ayuda de esta sonda hasta un $78 \%$ de los pacientes obstruidos por adherencias se han recuperado, requiriéndola en un promedio de 6 días.

Intubación del intestino delgado: con tubo de Miller Abbott o de cantor, tiene las siguientes indicaciones:

1. Resolución de una obstrucción

2. Obstrucciones leves. Se resolverán en un 50 a $60 \%$ en el periodo posoperatorio inmediato.

3. Obstrucción debida a enfermedad inflamatoria que se espera se resuelva de manera segura con manejo médico.
Uso de antibióticos: generalmente se indica la cobertura contra bacterias Gram negativas y bacterias anaerobias, ya que es muy posible que por el compromiso circulatorio se presente cierto grado de translocación bacteriana. Si de acuerdo a la patología de base existe un proceso infeccioso éste deberá de tratarse adecuadamente con estos medicamentos ${ }^{(8)}$.

\section{Tratamiento \\ Quirúrgico}

La patología obstructiva es una indicación quirúrgica en la mayoría de los casos, que requerirá de laparotomía exploradora y manejo de la etiología con extirpación, puenteo, resección intestinal, angioplastía, corte y ligadura, dependiendo de los hallazgos y finalmente, lavado más drenaje de la cavidad, así como la corrección de la causa subyacente.

Los tipos de manejo quirúrgico se dividen en tiempos quirúrgicos:

Cirugía de un solo tiempo quirúrgico: cuando se realiza la resección del segmento afectado y anastomosis primaria con drenaje y lavado de la cavidad. Aunque este método no es el preferido de los cirujanos por el alto riesgo que conlleva en la cirugía, sobre todo de urgencia, cuando el hallazgo es en el transoperatorio, ya que existe un riesgo muy alto de dehiscencia y fuga de la anastomosis con sepsis por la falta de preparación adecuada del intestino.

Cirugía en dos tiempos quirúrgicos: el primero con la resección del segmento afectado $\mathrm{y}$ colostomía derivativa temporal, el segundo tiempo con el desmantelamiento de la colostomía y la realización de su anastomosis en un tiempo de 4 a 6 meses posteriores a la primera cirugía o de acuerdo a su evolución clínica. Se ha llegado a anastomosar en un término de 6 semanas por gastos muy altos y descompensación por deshidratación severa en pacientes ambulatorios a quienes se les ha realizado ileostomía derivativa temporal por patología de tipo benigna, así como por intolerancia física, como sucede en las reacciones alérgicas al material adhesivo de las bolsas de colostomía, causando un eczema severo o por intolerancia psicológica al estoma, como en los pacientes con yeyunostomías en pacientes ancianos o en muy jóvenes, como los adolescentes con trauma abdominal que ameritaron manejo de este tipo. 
Cirugía en tres tiempos quirúrgicos: consiste en la derivación temporal con estoma, el tumor in situ y cierre del segmento distal, seguida de resección del tumor y finalmente seguida en el último tiempo de la anastomosis ${ }^{(9)}$.

\section{CONCLUSIONES}

La obstrucción intestinal recurrente ocurre en un $10 \%$ en pacientes tratados con adherólisis y esta incidencia aumenta con cada intervención subsecuente.

Pacientes con adherólisis múltiples se beneficiarán de una pexia organizada de las asas, para promover la producción de adherencias organizadas de una manera no obstructiva: plicatura transmesentérica. Los puntos seromusculares se utilizarán para plicar las asas adyacentes, previa maniobra de Noble (para acomodar las asas).

La aplicación intraoperatoria del tubo de Leonard o de Baker a través de una gastrostomía o de una yeyunostomía alta, dejándolo en la luz por 12 a 14 días, tiene una dureza suficiente para dejar las asas en posición hasta que se forman adherencias de forma no obstructiva.

No existe un método totalmente seguro que no produzca adherencias, sin embargo, la limpieza y el lavado generoso con abundante solución salina es extraordinariamente beneficioso.

La mortalidad operatoria depende del sitio de obstrucción y depende de la causa. Se acepta que en términos generales es $\mathrm{de}^{(10)}$ :

- Obstrucción de intestino delgado: 0-5\%

- Obstrucción de colon.

- $1-5 \%$ en diverticulitis.

- $5-10 \%$ en carcinoma.

- $40-50 \%$ en vólvulos con necrosis colónica.

\section{REFERENCIAS BIBLIOGRÁFICAS}

1. Vargas DA. Gastroenterología. 2a . Edición. 1998. Ed.McGraw-Hill Interamericana.

2. Vicario SJ Glover JL. Obstrucción intestinal. En: Tintinalli JE, Krome RL, Ruiz E. Medicina de Urgencias. $4^{\mathrm{a}}$ edi- ción. 1998. Interamericana McGraw Hill. México.

3. Welch JP. Bowel obstruction. Differential diagnosis and clinical management. Saunders, 1990.

4. Samel S Keese M Kleczka M et al. Microscopy of bacterial translocation during small bowel obstrtuction and ischemia in vivo-a new animal model. BMC Surgery. 2002;2:6.

5. O'Sullivan D O'Riodain M O'Connell RP Dineen M Brady MP. Peritoneal adhesion formation afternlysis: inhibition by polyethylene glycol 4000. Br J Surg. 1991;78(4):427-429.

6. Lewis LM Banet GA Blanda M. Etiology and clinical course abdominal pain in senior patient. A prospective multicenter study. J Gerontolol Biol Sci Med. 2005;60(8);1071-1076.

7. Megibow AJ Balthazar EJ Cho KC Medwid SW Birnbaum BA Noz ME. Bowel obstruction. Evaluation with CT. Radiology. 1991;180(2):313-318.

8. Snyder CL Ferrell KL Goodale RL Leonard AS. Nonoperative management of small bowel obstruction with endoscopic long intestinal tube replacement. Am Surgeon 1990;56(10):587-592.

9. Ellis CN Boggs HW Slagle GW Cole PA. Small bowel obstruction after colon resection for benign and malignant diseases. Dis Colon Rectum. 1991;34(5): 367-371.

10. Livingston EH Passaro EPJ. Postoperative ileus. Dig Dis Sci. 1990;35(1):121132.

\section{DECLARACIÓN DE CONFLICTO DE IN- TERESES}

Los autores declaran que no existen conflictos de intereses. 